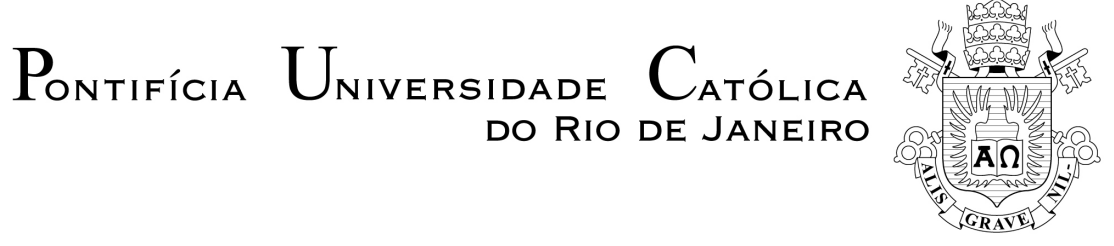

Rafael Sabbagh Armony

Fatores Críticos para a Prática de Valores Ágeis em Equipes de Tecnologia da Informação

Dissertação de Mestrado (Opção profissional) Dissertação apresentada como requisito parcial para obtenção do título de Mestre pelo Programa de PósGraduação em Administração de Empresas da PUCRio.

Orientadora: Ana Heloisa da Costa Lemos

Rio de Janeiro, agosto de 2010 
Pontifícia Universidade Católica $_{\text {do }}$ DO RIO DE JANEIRO

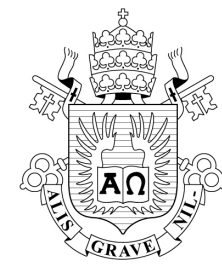

Rafael Sabbagh Armony

\title{
Fatores Críticos para a Prática de Valores Ágeis em Equipes de Tecnologia da Informação
}

\begin{abstract}
Dissertação apresentada como requisito parcial para obtenção do título de Mestre pelo Programa de PósGraduação em Administração de Empresas da PUC-Rio. Aprovada pela Comissão Examinadora abaixo assinada.
\end{abstract}

\author{
Prof ${ }^{a}$. Ana Heloisa da Costa Lemos \\ Orientadora \\ Departamento de Administração - PUC-Rio
}

Prof ${ }^{\mathrm{a}}$. Sandra Regina da Rocha Pinto Departamento de Administração - PUC-Rio

Prof. Rodrigo Penteado Ribeiro de Toledo Centro de Pesquisa e Desenvolvimento Leopoldo Américo Miguêz de Mello, Superintendência de Pesquisa, Exploração e Produção 
Todos os direitos reservados. É proibida a reprodução total ou parcial do trabalho sem autorização da universidade, do autor e do orientador.

\section{Rafael Sabbagh Armony}

Graduou-se em Engenharia de Computação pela PUC-Rio em 1999. Trabalha na área de tecnologia da informação desde o início de sua carreira profissional, exercendo inicialmente a função de desenvolvedor de software e posteriormente a de líder de equipes e gerente de projetos. Atualmente trabalha como ScrumMaster, Scrum coach e dá palestras em empresas e eventos sobre gerência Ágil de projetos e desenvolvimento Ágil de software. Em 2007, concluiu o MBA em Gestão Empresarial (IAG Management) pela PUC-Rio.

Ficha Catalográfica

Armony, Rafael Sabbagh

Fatores críticos para a prática de valores ágeis em equipes de tecnologia da informação / Rafael Sabbagh Armony ; orientadora: Ana Heloisa da Costa Lemos. - 2010. 196 f. : il. ; $30 \mathrm{~cm}$

Dissertação (Mestrado)-Pontifícia Universidade Católica do Rio de Janeiro, Departamento de Administração, 2010.

Inclui bibliografia

1. Administração - Teses. 2. Valores ágeis. 3. Projetos. 4. Equipes. I. Lemos, Ana Heloisa da Costa. II. Pontifícia Universidade Católica do Rio de Janeiro. Departamento de Administração. III. Título.

CDD: 658 
Ao eterno Professor José Roberto Gomes da Silva, que partiu cedo demais sem que pudéssemos terminar este e tantos outros futuros trabalhos.

À minha filha Clara, que acabou de chegar e já significa tudo para mim. À minha mulher, Maria José, a meus pais, Miguel e Rejane e a meus irmãos, Nathália e Flávio pela inspiração, apoio e carinho. 


\title{
Agradecimentos
}

\begin{abstract}
À minha orientadora, Ana Heloisa da Costa Lemos, por ter aceitado o desafio de recomeçar este trabalho junto comigo. Por me orientar - ensinar, sugerir, apressar, apoiar, receber, buscar, acalmar e cobrar - sempre na medida certa.
\end{abstract}

Ao professor José Roberto Gomes da Silva pelas longas conversas no pátio do IAG, enquanto definíamos as direções deste trabalho. Por ter me dado a honra de aceitar ser meu orientador, embora o imponderável tenha dado um rumo diferente a essa história.

À minha mulher Maria José Levy Ibarra pela paciência, carinho, dedicação e compreensão pelas horas que deixamos de estar juntos para que eu pudesse realizar este trabalho.

À comunidade de praticantes de Scrum do Brasil, em particular aos membros da lista de e-mails scrum-brasil, a partir da qual consegui muitos dos contatos para a realização das entrevistas. 


\section{Resumo}

Armony, Rafael Sabbagh; Lemos, Ana Heloisa da Costa. Fatores Críticos para a Prática de Valores Ágeis em Equipes de Tecnologia da Informação. Rio de Janeiro, 2010. 196p. Dissertação de Mestrado (Opção profissional) - Departamento de Administração, Pontifícia Universidade Católica do Rio de Janeiro.

O uso de metodologias Ágeis vem se popularizando no mercado de projetos de tecnologia da informação (TI) como uma alternativa bem-sucedida às práticas e metodologias tradicionais, que muitas vezes não são adequadas ao cenário de mudanças e de trabalho criativo de projetos de TI, e assim vem sendo responsabilizadas pelo alto índice de fracasso em projetos que as aplicam nessa área. No entanto, a prática dos valores Ágeis por equipes de TI, essenciais para o sucesso no uso das metodologias e frameworks Ágeis, pode representar uma quebra de paradigma de difícil realização para a maioria das equipes. Este trabalho teve como objetivo a identificação e a análise dos principais fatores que facilitam e dos principais fatores que dificultam a prática de valores Ágeis por equipes no desenvolvimento de sistemas de TI, na perspectiva de membros e líderes dessas equipes, e as condições que influenciam a manifestação desses fatores. Para tal, foi realizado um estudo fenomenográfico, utilizando-se de entrevistas semi-estruturadas com membros e líderes de equipes Ágeis de desenvolvimento de sistemas de TI do Brasil. Os fatores críticos, uma vez identificados, foram classificados e analisados utilizando-se referências teóricas da Administração com ênfase na teoria da Produção Enxuta, complementada por teorias de trabalho em equipes autogerenciadas, de motivação no trabalho, de relacionamento com o cliente e de participação do cliente na prestação do serviço.

\section{Palavras-chave}

valores ágeis; projetos; equipes 


\section{Abstract}

Armony, Rafael Sabbagh; Lemos, Ana Heloisa da Costa. Critical Factors for the Practice of Agile Values in Information Technology Teams. Rio de Janeiro, 2010. 196p. Msc. Dissertation - Departamento de Administração, Pontifícia Universidade Católica do Rio de Janeiro.

The use of Agile methodologies is gaining popularity in the information technology (IT) project market as a successful alternative to traditional practices and methodologies, which are often not appropriate to the scenario of change and creative work of IT projects, and this way have been blamed for the high rate of failure in projects that apply them in that area. However, the practice of Agile values by IT teams, essential for the successful use of Agile methodologies and frameworks, may represent a paradigm shift of difficult achievement for most teams. This study aimed to identify and analyze the main factors facilitating and main factors hindering the practice of Agile values by IT system development teams, from the perspective of members and leaders of these teams, and the conditions that influence the manifestation of these factors. To this end, we performed a phenomenographic study, using semi-structured interviews with members and team leaders of Agile IT system development teams from Brazil. The critical factors, once identified, were classified and analyzed using theoretical references of Business Administration with an emphasis on the theory of Lean Production, complemented by theories of self-managed work teams, motivation at work, customer relations and customer participation on service production.

\section{Keywords}

agile values; projects; teams 


\section{Sumário}

1 Introdução 14

1.1. Problema de Pesquisa 14

1.2. Objetivos 16

1.3. Questões de Pesquisa 16

1.4. Relevância do Estudo 17

1.5. Delimitações do Estudo 18

1.6. Estrutura da Dissertação 19

2 Referencial Teórico $\quad 21$

2.1. Agilidade 22

2.1.1. Introdução à Agilidade 22

2.1.2. Definições de Agilidade 23

2.1.3. Os Valores Ágeis $\quad 24$

2.1.3.1. Indivíduos e Interações 24

2.1.3.2. Software em Funcionamento 26

2.1.3.3. Colaboração com o Cliente 26

2.1.3.4. Responder a Mudanças 27

2.1.4. Os Princípios Ágeis 28

2.2. Scrum 29

2.2.1. Introdução ao Scrum $\quad 29$

2.2.2. Visão Geral do Ciclo do Scrum 31

2.2.3. Os Papéis no Scrum 32

2.2.4. Os Artefatos do Scrum 34

2.2.5. Os Eventos do Scrum 36

2.3. Produção Enxuta 38

2.3.1. O Sistema Toyota de Produção e a Produção Enxuta 38

2.3.2. Os Princípios da Produção Enxuta 41

2.3.2.1. Desperdício no Trabalho 42

2.3.2.2. Melhoria Incremental Contínua 44

2.3.2.3. Produção de Valor para o Cliente 48 
2.3.2.3.1. Definição de Valor 48

2.3.2.3.2. Produção de Valor em Fluxo 49

2.3.2.3.3. Produção de Valor "Puxada" pelo Cliente 50

2.4. O Cliente na Prestação de Serviços 52

2.4.1. Participação do Cliente na Produção de Valor 52

2.4.2. Relacionamento com o Cliente 53

2.5. Trabalho em Equipe 55

2.5.1. Definição de Equipes de Trabalho 55

2.5.2. Equipes de Trabalho Autogerenciadas 55

2.5.3. O Sistema Toyota de Produção e as Equipes de Trabalho 56

2.5.4. Liderança em Equipes de Trabalho Autogerenciadas 57

2.5.5. Efetividade de Equipes de Trabalho Autogerenciadas 58

2.5.6. Interação entre Membros de Equipes de Trabalho 62

2.6. Motivação no Trabalho 64

2.6.1. Introdução à Motivação no Trabalho 64

2.6.2. Teorias sobre a Motivação no Trabalho 66

2.6.2.1. A Teoria ERC 66

2.6.2.2. A Teoria das Necessidades Adquiridas 68

2.6.2.3. A Teoria da Fixação de Objetivos 69

2.6.2.4. A Teoria das Características do Trabalho 72

3 Metodologia da Pesquisa $\quad 76$

3.1. Tipo de Pesquisa 76

3.2. Papel do Pesquisador $\quad 79$

3.3. Seleção de Sujeitos $\quad 81$

3.4. Procedimentos de Coleta e Registro de Dados 83

3.5. Limitações do Método 85

4 Análise dos Resultados 86

4.1. Introdução 86

4.2. Fatores Críticos para a Prática de Valores Ágeis 89

4.2.1. Promoção de Melhorias Incrementais Contínuas nos

Processos de Produção Realizada pela Equipe 89

4.2.1.1. Realização Sistemática de Reuniões de Melhorias 
$\begin{array}{ll}\text { Incrementais } & 90\end{array}$

4.2.1.2. Acompanhamento e Realização das Melhorias Levantadas 94

4.2.1.3. Apoio da Organização à Realização de Mudanças pela Equipe 96

4.2.1.4. Viabilidade na Realização de Melhorias Levantadas 97

4.2.1.5. Estabilidade na Composição da Equipe 98

4.2.2. Motivação da Equipe 99

4.2.2.1. Senso de Realização dos Membros da Equipe com o

Trabalho

100

4.2.2.2. Perspectiva dos Membros da Equipe de Evolução de

Carreira Dentro da Organização 104

4.2.2.3. Qualidade do Relacionamento entre Membros da Equipe 105

4.2.2.4. Atendimento às Necessidades Básicas de Produção da

Equipe

107

4.2.2.5. Constância e Sustentabilidade no Ritmo de Produção da

Equipe

108

4.2.2.6. Poder de Decisão e Ação da Equipe Quanto à Produção 109

4.2.3. Esforço da Equipe na Redução do Desperdício na Produção

4.2.3.1. Crença da Equipe nos Valores Ágeis como Redutores de Desperdício

4.2.3.2. Superação das Dificuldades Intrínsecas à Criação de

Soluções Simples

4.2.3.3. Compreensão da Cadeia de Valor do Produto pela Equipe

4.2.3.4. Contribuição do Cliente na Produção de Valor

4.2.4. Produção Rápida de Valor pela Equipe

4.2.4.1. Conhecimento das Regras de Negócios na Organização

4.2.4.2. Estrutura Básica de Apoio à Produção

4.2.4.3. Planejamento e sua Execução na Produção

4.2.4.4. Concentração dos Esforços da Equipe na Produção de Valor

4.2.4.5. Visão do Produto pela Equipe

4.2.4.6. Diversidade de Conhecimentos e Habilidades Dentro da

4.2.4.7. Uso de Conhecimentos Técnicos e Boas Práticas

4.2.4.8. Contribuição do Cliente na Produção de Valor

4.2.5. Entregas Frequentes de Valor para o Cliente 
4.2.5.1. Autocobrança da Equipe por Entregas Frequentes

4.2.5.2. Expectativa do Cliente por Entregas Frequentes

4.2.5.3. Minimização dos Impactos das Entregas

4.2.5.4. Momento do Cliente para Entregas

144

4.2.5.5. Compreensão do Conteúdo das Entregas pelo Cliente

145

4.2.5.6. Produção Rápida de Valor pela Equipe

146

4.2.6. Poder de Decisão e Ação da Equipe Quanto à Produção

4.2.6.1. Promoção de Poder da Equipe por um Líder

4.2.6.2. Confiança da Organização nas Decisões da Equipe Quanto à Produção

4.2.6.3. Nivelamento Técnico entre Membros da Equipe

4.2.6.4. Maturidade da Equipe

4.2.6.5. Qualidade da Comunicação entre Membros da Equipe

4.2.6.6. Perfil dos Membros da Equipe Quanto à Agilidade

4.2.6.7. Autorregulação Quanto ao Comprometimento 160

4.2.7. Contribuição do Cliente na Produção de Valor

4.2.7.1. Compromisso do Cliente com o Valor

4.2.7.2. Nível Realista de Demanda do Cliente

4.2.7.3. Facilitação pelo Cliente do Acesso da Equipe às Regras de Negócio de Maior Valor

4.2.7.4. Identificabilidade e Acessibilidade do Cliente

4.2.7.5. Qualidade da Comunicação entre Cliente e Equipe

4.2.8. Confiança do Cliente na Equipe

4.2.8.1. Maturidade da Relação entre Equipe e Cliente

4.2.8.2. Afinidade do Cliente com a Agilidade

4.2.8.3. Compatibilidade do Contrato com o Cliente com a Agilidade 


\section{Lista de figuras}

Figura 1: O Ciclo do Scrum, adaptado de Schwaber \& Beedle, $2002 \quad 32$ 


\section{Lista de quadros}

Quadro 1: Perfil dos Entrevistados 82

Quadro 2: Roteiro da Entrevista 83

Quadro 3: Fatores críticos e condições que influenciam sua

manifestação 88

Quadro 4: Fator crítico "promoção de melhorias incrementais

contínuas nos processos de produção realizada pela equipe" e condições que influenciam sua manifestação 89

Quadro 5: Fator crítico "motivação da equipe" e condições que influenciam sua manifestação

Quadro 6: Fator crítico "esforço da equipe na redução do desperdício na produção" e condições que influenciam sua manifestação

Quadro 7: Fator crítico "produção rápida de valor pela equipe" e condições que influenciam sua manifestação

Quadro 8: Fator crítico "entregas frequentes de valor para o cliente" e condições que influenciam sua manifestação

Quadro 9: Fator crítico "poder de decisão e ação da equipe quanto à produção" e condições que influenciam sua manifestação

Quadro 10: Fator crítico "contribuição do cliente na produção de valor" e condições que influenciam sua manifestação

Quadro 11: Fator crítico "confiança do cliente na equipe" e condições que influenciam sua manifestação 